\title{
doispontos:
}

\section{Assentimento religioso e Filosofia no Fasl al-maqal de Averróis}

\author{
Religious assent and Philosophy in Averroes' Fasl al-maqal
}

\author{
Arthur Klik \\ Universidade Federal de Lavras - UFLA \\ arthurklik@yahoo.com.br
}

\begin{abstract}
Resumo: O Fasl al-maqal, umas das obras originais de Averróis, se destaca por seu caráter polêmico. Sendo redigida como um pronunciamento jurídico, tem como um de seus objetivos principais analisar o estatuto da filosofia em face da Lei islâmica, ao verificar qual é a atitude que deve ser adotada por todo aquele que travar contato com as obras da antiguidade grega. Em um cenário em que a legitimidade da filosofia se coloca em questão, o diagnóstico e a solução propostos por Averróis se destacam ao apresentar uma interpretação singular da Lei ante a filosofia, concebendo a segunda como um elemento necessário para a saúde da comunidade. Este artigo pretende analisar essa interpretação, na qual três pontos se colocam na consideração da relação entre filosofia e revelação: o (1) asseguramento da possibilidade do assentimento religioso individual e (2) da manutenção do bem-estar geral junto à (3) possibilidade de se afirmar a legitimidade de um intérprete que garanta o assentimento correto aos crentes não filósofos.
\end{abstract}

Palavras-chave: Averróis, Fasl al-maqal, Shari'a, falsafa, crente filósofo, crente não filósofo.

Abstract: An original work of Averroes, the Fasl al-magal is remarked by its controversial character. Composed as a juridical statement, one of its main goals is to analyze the role of philosophy in Islamic Law determining which attitude must be adopted by those aware of the works of Greek antiquity. Facing a problematic scenario in which the legitimacy of philosophy is putted in question, the diagnosis and solution proposed by Averroes emphasizes a unique interpretation of the Law guided by Philosophy devised as a required element to achieve community welfare. This article intends to analyze that interpretation in which three points arise about the relationship between philosophy and revelation: (1) the insurance of the individual possibility of religious assent; (2) the endurance of common welfare, both associated to (3) the possibility of assert the legitimacy of an interpreter able to assure the correct assent to common believers.

Keywords: Averroes, Fals al-maqual, Shari'a, falsafa, philosopher believer, common believer. 
O movimento de recepção e apropriação da filosofia antiga pela Falsafa ${ }^{1}$ se constituiu como um período de extrema atividade intelectual entre esses povos. Em aproximadamente seis séculos, este trabalho de recepção deu origem a uma longa lista de comentários e textos autorais, que enfrentaram problemas filosóficos advindos da antiguidade, também aprimorando, a partir deste contato, diversas questões relacionadas ao cenário conceitual do Islã. Vale destacar que o contato estabelecido entre a herança conceitual da antiguidade e o contexto político-religioso no qual se desenvolve a Falsafa não ocorrerá sem grandes inquietudes. Mesmo que se possa considerar, neste contexto, que a antiguidade tenha sido tomada apenas como horizonte paradigmático de questões, diversas incompatibilidades serão enfrentadas por aqueles que não apenas buscaram investigar o conhecimento desenvolvido por esta herança grega, mas que parecem ter tomado para si a missão de continuar sua ciência. É possível encontrar registros desta autodeclarada vocação ao longo da filosofia árabe, que consideram fundamentais a recepção e a continuidade do estudo do que foi desenvolvido pela antiguidade como imagem de um progressivo desenvolvimento da humanidade em direção ao conhecimento.

\begin{abstract}
Assim, se for reunido o pouco do que cada um deles obteve da verdade, então, se coleta uma porção valiosa. Por isso, devemos ampliar o nosso agradecimento aos que nos trouxeram o mínimo da verdade - e ainda mais aos que nos trouxeram muito da verdade - por terem compartilhado conosco os frutos de seu pensamento e nos facilitado $\mathrm{o}$ acesso às questões verdadeiras obscuras, beneficiando-nos com as premissas que nos facilitam os caminhos da verdade. (Al-Kindi, 2014, p. 49).
\end{abstract}

O trecho citado acima foi extraído da Filosofia Primeira de Al-Kindi, que manifesta um dos primeiros registros do que pode ser compreendido como uma tentativa de elaborar respostas para questões próprias a seu contexto religioso, mobilizando categorias da antiguidade grega, principalmente da obra de Aristóteles e do neoplatonismo ${ }^{2}$. Devido a esse tratamento das questões, Al-Kindi pode ser considerado o primeiro dos Falasifah, de maneira que é possível observar o mencionado caráter de continuidade que a recepção da filosofia antiga adquire para este pensador, cuja expressão desta premissa pode ser explicitamente observada em suas obras (Cf. FAKHRY, 1968, p. 78-79).

Averróis, alguns séculos depois, também estará diretamente envolvido nesta tarefa continuadora que nossa breve menção ao primeiro dos falasifah procura ilustrar (Cf. FAKHRY, 1968, p. 82). É possível aproximar esta inclinação entre ambos, já que diversos momentos de sua obra nos permitem observar que a presença da antiguidade também se mostra em Averróis como fonte de premissas investigativas, a partir das quais o sábio, ou todo aquele que busca a sabedoria, deve se colocar como continuador.

Tornou-se evidente, a partir daí, que o estudo da obra dos antigos é obrigatório pela Lei religiosa, pois que a intenção de seus escritos e o propósito deles são o mesmo propósito que a Lei pressupõe para se enraizar. (AVERROES, 2005, p. 15).

\footnotetext{
${ }^{1}$ Resumidamente, período circunscrito entre os séculos VIII e XII d.C., em que os territórios controlados pelo Islã travam contato com autores e obras da antiguidade grega. O termo falsafa é a transição para o árabe da palavra filosofia em grego. E diz respeito, especificamente, ao tipo de ciência praticada pelos gregos.

${ }^{2}$ Importante mencionar que um texto apócrifo, intitulado "Teologia de Aristóteles", constituiu uma das principais fontes, sobretudo para Al-Kindi, desta presença neoplatônica (Cf. PSEUDO-ARISTÓTELES, 2010).
} 
Talvez a mais famosa manifestação desta tentativa de continuidade possa ser lida no Kitab Fasl al-maqal wa taqrir ma bayn ash-shari'a wal-hikma min al-ittisal', um de seus textos mais polêmicos e conhecidos. Nesta fatwa $a^{4}$, está em jogo o que seu longo título destaca: "O discurso decisivo no qual se estabelece a conexão existente entre a revelação e a filosofia”. Além disso, a relação que é manifesta a partir deste título parece-nos suficiente para que fique clara a amplitude da problemática que Averróis enfrenta nesta obra, a de pensar o horizonte da filosofia em sua relação com o Islã de seu tempo. Segundo Geoffroy, este contexto nunca havia enfrentado tal questão do ponto de vista de sua licitude (Cf. GEOFFROY, 1999, p. 10).

É importante lembrar que esta obra se desenvolve em meio a um contexto político no qual se manifestam posições antagônicas no que diz respeito aos encaminhamentos teóricos e práticos do Islã, bem como nas próprias considerações a respeito da natureza do homem e de tudo aquilo que este desenvolve como sua atividade própria. $\mathrm{O}$ enfrentamento destes pontos por Averróis conduzirá o exercício da filosofia para o centro da discussão, apontando-a como elemento fundamental para o encaminhamento adequado destas questões. Uma das consequências mais diretas de sua análise é que a posição que cabe ao filósofo no interior de sua comunidade torna-se necessária e fundamental para a manutenção adequada de sua estrutura (Cf. MAKKI, 1993, p. 20).

A orientação individual das ações praticadas pelos homens parece ter um papel central na consideração de Averróis, e não apenas a orientação geral da comunidade na qual eles se inserem. Estes dois aspectos são fundamentais para o que se pode chamar de "bem-estar geral" em sua relação com a Lei divina (BUTTERWORTH, 2007, p. 190). Por isso, é também fundamental compreender como desenvolve seu pensamento em meio a posições conflitantes em relação ao âmbito religioso, visto que ele parece ter em mente dois aspectos fundamentais relativos ao direito islâmico (fiqh): (1) o estabelecimento de um consenso como forma de adesão popular a uma questão de ortodoxia religiosa; (2) e quais são os elementos que garantem a efetividade do assentimento individual.

Estes dois pontos podem ser questionados do seguinte modo: (2) se é possível afirmar que a onipotência divina é um fundamento que não pode ser negado por um fiel; (1) também sendo necessário considerar que há muita divergência em relação a sua natureza, que poderá ser modificada por interpretações conflitantes. A filosofia parece se colocar exatamente entre os dois elementos mencionados; (2) como garantia da possibilidade do assentimento religioso individual, aplicando a demonstração à solução dos conflitos entre as interpretações, (1) e também assegurando que o consenso popular esteja de acordo com os resultados da demonstração. Em outras palavras, o que parece estar em jogo é a salvação individual e a estabilidade política (Cf. BELO, 2016, p. 37).

\footnotetext{
${ }^{3}$ Vale mencionar o grande número de traduções que o texto possui para diversos idiomas. Destacamos as traduções para o inglês de Charles Butterworth (2008), Georges Hourani (1976); em espanhol de Manuel Alonso (1947), Vera Yamumi Tabuch (1996), e Rafael Ramón Guerrero (1998); em francês de Marc Geoffroy (1996); em italiano de Massimo Campanini (1994); em Alemão de Frank Griffel (2010); em português de Márcia Valéria (2005), e Catarina Belo (2006). Utilizaremos a tradução para o português de Márcia Valéria (AVERROES, 2005), cotejada pelas traduções de Marc Geoffroy (GEOFFROY, 1998), George Hourani (HOURANI, 2012) e Charles Butterworth (BUTTERWORTH, 2001). Esta obra faz parte de um conjunto que, segundo Fakhry, representa o fundamental para compreensão do que pode ser chamado de o pensamento autônomo de Averróis. As outras obras são: Kitab al-Kashf 'an manahij al-adilla, ou "Desenvolvimento dos métodos de demonstração dos dogmas da religião muçulmana”; Tahafut al-Tahafut, ou "A Incoerência da Incoerência” (Cf. FAKHRY, 1968, p. 78).

${ }^{4}$ Uma fatwa é um parecer de natureza jurídica, que tem como objetivo divulgar o parecer do juiz a respeito de uma questão em particular, neste caso, a relação entre a revelação e a filosofia (NANJI, 2008, p. 87).
} 
Neste sentido, é possível observar que Averróis parece indicar que uma das grandes fontes de interpretações conflitantes esteja centralizada na figura de al-Ghazali $^{5}$. O que também pode nos conduzir a uma terceira questão, pois a pergunta que parece se colocar mais imediatamente é também sobre o controle da cidade, ou ainda, sobre o modo pelo qual este controle será exercido. Quem será o intérprete autorizado pela escritura, na ausência do profeta, a conduzir os homens da maneira correta a seu assentimento e a prática religiosa? Para Mensia, o que irá motivar a redação do Fasl al-maqal, bem como do Kash an manahij e do Tahafut al-Tahafut, é exatamente o conflito impulsionado pela obra de al-Ghazali (Cf. MENSIA, 2019, p. 41).

Temos em mente, neste artigo, a análise da solução fornecida por Averróis no Fasl al-maqal para estas questões, que parecem estar mais diretamente implicadas na tese manifesta pelo título da obra, a saber, sobre a conexão entre a filosofia e a revelação. Em resumo, analisaremos sua solução para o aparente conflito entre a filosofia e a revelação, tendo em conta necessidade de garantia do assentimento religioso individual, a manutenção do bem-estar social, e a escolha de um intérprete legítimo para o Livro Sagrado.

\title{
Justificar a filosofia
}

Uma das premissas iniciais do Fasl al-maqal é a análise do estatuto que a filosofia ocupa na vida dos homens, e de verificar se sua prática está em acordo com aquilo que Lei religiosa (Shari'a) ${ }^{6}$ autoriza, ou se este exercício afasta os homens do caminho da religião.

\begin{abstract}
[...] o alvo deste discurso é o de examinarmos, do ponto de vista da Lei religiosa, se o estudo da filosofia e das ciências da lógica é permitido pela Lei ou por ela proibido, ou ainda, se é prescrito, seja como recomendação, seja como obrigação (AVERROES, 2005, p. 03).
\end{abstract}

É neste sentido que ele buscará analisar o estatuto da autorização ou da proibição do acesso aos livros de demonstração (kitab al-burhan) e à prática desta ciência pelos homens. Marc Geoffroy aponta que esta passagem corresponde ao âmbito das cinco qualificações que o direito islâmico (fiqh) estabelece a respeito dos atos humanos (Cf. GEOFFROY, 1996, p. 175) ${ }^{7}$. A passagem supracitada parece direcionar a ênfase para três aspectos, a proibição (haram), a recomendação (mandub 'ilay-hi), e a obrigação (wajib). O que parece estar em jogo na discussão é primeiramente a proibição; a defesa da filosofia realizada na primeira parte do texto tem em mente afastar essa qualificação, que interditaria completamente a sua prática. Em segundo lugar, afastada a tese da proibição, caberá compreender qual é a natureza de sua prática, se é algo recomendável a todo fiel que se encontre em condições de realizá-la, ou se é uma obrigação a ser cumprida por todos (Cf. TAYLOR, 2014, p. 458).

Para Averróis, proibir o acesso dos homens capacitados ao Livro Sagrado leva a consequências graves, pois exclui destes homens a própria possibilidade de alcançar adequadamente seu assentimento (tasdiq) religioso, de realizar seu movimento interno de reconhecimento da religião (Cf. BELO, 2016, p. 38). Ao conceber que cada homem pode utilizar-se de seus próprios meios para se aproximar do conhecimento de Deus, valendo-se das condições que possui para compreender, parece estar em jogo o estabelecimento

\footnotetext{
${ }^{5}$ A obra de al-Ghazali era muito popular nos tempos de Averróis. Também é válido mencionar sua rejeição à filosofia. Averróis se posiciona contra ele em diversas obras, tendo dedicado uma obra, Tahafut al- Tahafut, para refutá-lo a partir de sua própria obra, o Tahafut al-falasifah. (WOHLMAN, 2010.) Em seu artigo Les deux facetes de l'unique vérité. Révélation Coranique et excellence humaine' selon Averroès, afirma também que o Fasl al-maqal seria uma das reações de Averróis ao tumulto provocado por AlGhazali (Cf. WOHLMAN, 2004, p. 582).

${ }^{6}$ Os pontos fundamentais da Shari’a são o Corão e a Sunna. No entanto, as divergências são tratadas a partir do estabelecimento do consenso (Lyma) e da analogia (Qyias). (Cf. MAKKI, 1993, p. 21)

${ }^{7}$ A classificação dos atos humanos está dividida em cinco categorias, os atos: os permitidos pela lei, os recomendados, os obrigatórios, os condenáveis e os interditos. A lei islâmica prevê os níveis de punição e premiação das ações humanas a partir desta classificação.
} 
de uma via dinâmica para o assentimento, pois cada homem poderá aproximar-se conforme aquilo que lhe é próprio, quer seja por meio de uma imagem individual superficial, quer seja por um silogismo demonstrativo. O ponto em questão é que qualquer prática que envolva a parte calculativa da alma estará sujeita a enganos, exatamente por sua inexatidão, o que não significa que tais sejam suficientes para gerar uma proibição à prática desta ciência (Cf. MAKKI, 1993, p. 25-26).

Averróis situa este mal provocado por um engano como ocasional, fruto da compreensão limitada dos enunciados que constituem o raciocínio, que levaria os homens a conclusões errôneas sobre a religião. Para ele, a prática da ciência demonstrativa é necessária para que os homens possam se aproximar em compreensão de aspectos relativos à causalidade divina, que suprimiriam este mal superficial ao apontar sua finalidade universal, que não é em si mesma má. Neste sentido, o verdadeiro mal repousa nas mãos dos homens que, dotados de uma interpretação dialética dos dogmas da religião, tentariam conduzir as massas afirmando-se como dotados de um conhecimento universal que na verdade não possuem (Cf. BUTTERWORTH, 1972, p. 900).

A dialética não constitui um mal, e a única limitação relacionada a ela está no fato de que suas premissas sejam derivadas da opinião, o que faz com que seus resultados careçam da precisão que pode ser alcançada a partir da demonstração (Cf. BUTTERWORTH, 1972, p. 895). Duas considerações importantes podem ser extraídas destes pontos: a primeira, que a ciência demonstrativa parece ser necessária para o assentimento religioso de certos homens; a segunda, que, por meio deste conhecimento, os homens se aproximam adequadamente de seu assentimento religioso. Isto também parece condicionar aquele que pretende se aproximar do Criador ao buscar o conhecimento de sua obra.

Se o ato de filosofar consiste na reflexão sobre os seres existentes e na consideração destes, do ponto de vista de que constituem a prova da existência do Artesão, quer dizer: enquanto são [semelhantes a] artefatos - pois certamente é na medida em que se conhece sua construção que os seres constituem uma prova da existência do Artesão; e se a Lei religiosa recomenda a reflexão sobre os seres existentes e mesmo estimula para isso, então é evidente que a atividade designada por esse nome (de filosofia) é considerada pela Lei religiosa seja como obrigatória, seja como recomendada (AVERROES, 2005, p. 03) .

O uso da demonstração não fere a ortodoxia da lei religiosa, mesmo que seu uso não esteja previsto pelo Corão ou pela tradição. Como justificativa para a proibição da filosofia, o argumento de que seu uso é uma inovação condenável (bi'da) fundamenta-se na ideia de que não há indicação corânica que o justifique. Averróis aponta que o uso jurídico do silogismo também não estava desde os primórdios associado ao Islã, tendo sido descoberto posteriormente e incorporado à tradição.

Por isso é fundamental utilizar o que foi analisado pela antiguidade: "[...] é preciso que avidamente tomemos em mãos seus livros, a fim de verificar tudo o que disseram a respeito. Se tudo for justo, aceitaremos [o que propõem]; e se se encontra algo que não seja justo, nós o indicaremos" (AVERROIS, 2005, p. 11). A ciência caminha de modo progressivo, sendo o patrimônio da atividade humana que reflete o exercício da racionalidade como um todo, em sua existência junto à humanidade. $\mathrm{O}$ que foi deixado pelos antigos deve ser recuperado em nome desta continuidade da ciência (Cf. BELO, 2016, p. 26).

Obviamente, por se tratar de uma ciência, é muito natural que os homens cometam erros em seu desenvolvimento. A ciência jurídica no Islã, que foi a primeira a utilizar o silogismo como método de análise, teria produzido muitos erros, não em função de seu método ou da empregabilidade do silogismo,

\footnotetext{
${ }^{8}$ Marc Geoffroy (1996, p. 103, nota 03), na tradução desta passagem, expõe longamente o vínculo que Averróis procura estabelecer entre a natureza do conhecimento dos seres, que é manifesta por meio da demonstração, com o postulado corânico da obrigatoriedade que todo fiel tem em assentir a necessidade da existência divina, baseando-se no reconhecimento de sua própria condição de criatura. A tradução de Marcia Valéria Aguiar (2005, p. 03, nota 03) também aponta os versículos do Corão que podem sustentar essa passagem.
} 
mas porque foi realizada por homens falhos, que se entregaram a questões mundanas, e que prejudicaram o correto desenvolvimento desta ciência.

Quantos jurisconsultos, para quem sua ciência foi causa de pecarem contra a continência, mergulharam na vida mundana! E este é o caso da maior parte entre os jurisconsultos, ainda que sua ciência requeira, por essência, a virtude prática. Eis por que é lícito dizer que o que advenha de uma ciência que requer a virtude intelectual é suscetível de advir também de uma ciência que requer a virtude prática. (AVERRÓIS, 2005, p. 19).

Para ele, a mesma conclusão pode ser extraída para o caso da filosofia, pois justificar que seu estudo seja proibido, em função do mau uso que alguns homens fizeram dela, também é um erro. Neste caso, quem o proíbe comete um erro mais grave, pois comete uma falta de natureza essencial, ao passo que o homem que comete um equívoco na prática de uma ciência erra apenas de modo acidental. Deste modo, é mais grave que esta ciência seja proibida do que o fato de que alguns homens possam ter sido desencaminhados pelo uso que fizeram dela: "[...] de modo que não há razão pela qual se deva desprezar algo benéfico por natureza e por essência, por nele haver inconveniente por acidente” (AVERRÓIS, 2005, p. 17). Parece ser um erro fundamental proibir que os homens que tenham sua natureza voltada para o estudo da filosofia possam desenvolver tal ciência, pois significa impedir que sua característica mais nobre, e também a mais essencial, se desenvolva de modo a buscar sua plena atualidade (Cf. BELO, 2016, p. 38).

Neste sentido, é importante mencionar que a posição desenvolvida por Averróis em relação ao exercício da filosofia não é consensual em relação a seus contemporâneos. Para alguns destes, a filosofia constitui-se como uma prática investigativa cujo saldo crítico tem que contar com o afastamento das estruturas sociais em função do alcance de uma compreensão universal do mundo. O filósofo afastar-se-ia da vida cotidiana por sua compreensão, em alguma medida, privilegiada do universo.

Na mesma direção, isto parece estar mais diretamente relacionado ao entrave de natureza religiosa, o qual, por considerar que tal exercício conduziria os homens a uma verdade que não dependeria da revelação - ou, ainda, que a subverteria a seus interesses -, encontra graves problemas na prática investigativa da filosofia. Para Hourani (1978, p. 24), a queda de Averróis teria sido motivada pelo incômodo causado por sua defesa da filosofia entre os cidadãos de Córdoba, pois a orientação comum parecia indicar que os filósofos consideravam que a religião caberia apenas como ferramenta de controle, destinada aos indivíduos que não são capazes de alcançar conhecimento de natureza filosófica. Estes últimos, conhecedores de uma ciência mais próxima da verdade, estariam dispensados da compreensão vulgar religiosa, podendo aproximar-se do divino mais livremente.

Vale lembrar que, em função da natureza de seu conhecimento, a consideração de que o filósofo se torne um homem apartado do mundo é uma ideia que experimentou certa popularidade desde a antiguidade (Cf. GIOVANNI, 2019, p. 09). Córdoba, a cidade em que Averróis passou boa parte de sua vida, já havia conhecido dois pensadores cujas obras parecem indicar tal inclinação. Ibn Bajja (Avempace) e IbnTufayl, famosos conterrâneos de nosso autor, foram autores de obras que indicaram que a aproximação de um estado de sabedoria tem como uma de suas implicações certo afastamento da vida mundana'. A posição que será defendida por Averróis se opõe a essa visão, e indica que o papel do filósofo se integra à própria comunidade. Para além disso, a vida na comunidade é o que permite aos indivíduos alcançarem certo grau de perfeição.

Além disso, é importante considerar que interesses políticos, voltados para a adesão das massas a certas interpretações, poderiam ter em mente a legitimação de mecanismos de controle (Cf. BELO, 2016, p. 23).

\footnotetext{
${ }^{9}$ Duas obras que merecem destaque aqui são: O regime do solitário, de Ibn Bajja, e o Filósofo autodidata, de Ibn Tufayl. Resumidamente, pode-se dizer que ambas as obras indicam a filosofia como um caminho de aproximação ao divino, o que tem como consequência o afastamento progressivo deste mundo.
} 
Neste sentido, também é possível perceber a leitura de que a filosofia representa uma ameaça ao cumprimento da lei religiosa, por, aparentemente, dispersar os homens em uma prática individual investigativa, a qual não representa o consenso necessário para o estabelecimento de uma ordem.

A disputa entre filosofia e religião é velha conhecida dos pesquisadores de filosofia medieval, disputa que, no horizonte da falsafa, se expressa de maneira distinta em relação ao modo como ela foi amplamente conhecida no cristianismo. A filosofia parece nunca ter sido verdadeiramente institucionalizada pelos árabes, e seu debate se manteve nos limites de sua validade perante o texto revelado. Tendo diante de si diversas manifestações anti-filosóficas ${ }^{10}$, seu esforço de harmonização parece ter em mente essa possibilidade de institucionalização da filosofia, isto é, de colocá-la a serviço da revelação como um elemento central, ainda que complementar e não obrigatório para a salvação. Parece fundamental que, para Averróis, as manifestações da fé possam ser obtidas através de diferentes registros, garantindo à totalidade dos homens a possibilidade do assentimento religioso. Aos homens simples, a garantia do assentimento dá-se por meio de imagens e alegorias, enquanto, para os praticantes da ciência demonstrativa, a possibilidade de ultrapassar as imagens está relacionada ao quanto avançam no conhecimento demonstrativo (Cf. BELO, 2016, p. 34).

Não se trata exatamente de dispensar os homens da prática religiosa, mas apenas de considerar que certa compreensão vulgar da religião, imagética, não lhes cabe. Averróis não parece estar de acordo com nenhuma das posições, primeiramente por não as entender como opostas, mas sim como complementares. O papel da religião não pode ser descartado mesmo pelos homens da demonstração, pois é para aprimorar seu assentimento que lhes é a dada a permissão para que realizem seus procedimentos investigativos (CAMPANINI, 2007, p. 217). A ciência não é algo outro que uma prova da existência de Deus, e a chamada por Averróis de "a prova do Artesão" é uma das premissas investigativas do Fasl al-maqal. Como Deus pode não querer que um homem exercite sua capacidade mais nobre, a razão? E qual é a função da capacidade racional, senão a de apontar para o conhecimento do Criador a partir do conhecimento de sua criação?

\begin{abstract}
Que a Lei religiosa convide à reflexão racional sobre os seres existentes e requeira de nós conhecimento deles, isto é evidente por diversos versículos do Livro de Deus - bendito e louvado seja -, entre os quais: "Refleti, pois, ó vós que tendes clarividência". Este versículo mostra a necessidade do uso do silogismo racional, ou do racional e legal ao mesmo tempo; ou, por exemplo, o enunciado do Altíssimo: "E não olharam para o reino dos céus e da terra e para todas as coisas que Deus criou?", versículo que induz claramente ao exame racional de todos os seres existentes (AVERRÓIS, 2005, p. 05).
\end{abstract}

Esta tentativa de aproximação harmoniosa entre a revelação e o exercício filosófico tem como ponto central o estabelecimento, por meio desta conexão, de um regime em que a filosofia seja integrada positivamente ao escopo da vida humana, o que parece ser a sua solução para este suposto dilema de que os filósofos se afastaram da religião. Enquanto expediente metodológico, pode-se notar que investigação de Averróis nos comentários ao estagirita se concentra nos processos realizados pelos homens no que diz respeito ao conhecimento humano, ao passo que a análise em obras como o Fasl al-maqal parece inclinar-se para a compreensão destes processos de um modo mais amplo, seja integrado ao horizonte da vida cotidiana, seja em seu propósito mais amplo, que diz respeito à revelação (Cf. FARJEAT, 2014, p. 104). O caráter jurídico desta obra não parece limitar-se a um expediente regulador, ou apenas normativo, estabelecendo juridicamente os limites formais da possibilidade de relação expressa no título. O texto, embora de natureza epistolar e breve, tem em sua estrutura diversos apontamentos a respeito de uma compreensão mais ampla e integradora da revelação como orientação fundamental, não apenas dos homens simples, mas do próprio filósofo e sua atividade.

E compreender o estatuto da filosofia, seja como obrigação, recomendação, ou mesmo proibição, classificações próprias ao direito islâmico, tem em mente também o estabelecimento de uma sharia que

\footnotetext{
${ }^{10}$ Como a já mencionada obra de Al-Ghazali.
} 
se aproxime mais verdadeiramente do que é a própria religião. Se o Livro Sagrado pode ser compreendido com um guia para a conduta dos homens, a prática religiosa significa a aplicação deste guia, e compreendêla torna-se fundamental para todo aquele que tem como meta a verdadeira prática (Cf. FARJEAT, 2014, p. 102).

\section{O filósofo como guia}

O grande desafio parece ser o de legitimar que a racionalidade possua também os elementos necessários, para que, por meio de seu desenvolvimento, apreenda algo da verdade para além do que está manifesto na revelação. Não se trata de abandonar a religião em direção a uma espécie de religião filosófica, ou de uma crença na independência da razão, mas sim de um esforço em apontar que a racionalidade, manifestação do divino nos homens, é também a ferramenta do criador para que os homens possam compreender a criação (Cf. SARRIÓ, 2015, p. 60).

O alcance de uma atualidade da capacidade racional estará diretamente relacionado à percepção daquilo que está expresso na relação, vindo a justificá-la de maneira mais intensa do que em homens que não praticam esta ciência. Para Averróis, o verdadeiro filósofo, que realiza da maneira mais excelente o ideal da racionalidade, é aquele que se utiliza de sua ciência como um meio de aperfeiçoar seu assentimento religioso, e não para se afastar dele (CAMPANINI, 2007, p. 219). O verdadeiro filósofo é também um crente fervoroso, pois encontra por meio da filosofia os elementos universais para tornar sua fé mais sólida que a dos demais homens.

Este esforço em encontrar seu assentimento não pode ser impedido. Por isso, esses homens não podem ser proibidos de estudar a ciência demonstrativa, pois o criador não dotaria os homens de tal capacidade se o seu uso fosse proibitivo ou pecaminoso (Cf. BELO, 2016, p. 32). A verdadeira investigação filosófica é um caminho para o assentimento religioso. Este sentido confere um novo estatuto para a demonstração ( al-Burhân), que não é apenas recomendada, mas obrigatória para os casos em que o assentimento religioso dependa dela.

[...] equivale a proibir o sedento de beber água fresca e agradável até que morra de sede, pelo motivo de que outros que dela beberam engasgaram-se e morreram. Na verdade, a morte que resulta do engasgamento que a água possa produzir é de caráter acidental, enquanto a que decorre da sede é de caráter essencial e necessário (AVERRÓIS, 2005, p. 17).

Talvez a que mais se imponha neste contexto seja aquela relativa ao intérprete do texto sagrado. A grande disputa que se estabelece em torno da legitimidade da filosofia é também pautada pelo papel de legitimidade que esta ocupará dentro do horizonte religioso. Pois a acusação que se faz aos filósofos, neste contexto, é a de recorrerem ao expediente filosófico para desviar a necessidade da religião (FARJEAT, 2014, p. 110). Em outras palavras, a de pretenderem, por meio de explicações não piedosas, explicar o que já está compreendido na revelação, levando os homens ao erro em relação ao assentimento religioso e condenando-os. É preciso compreender o sentido que é dado por ele para que os homens possam ter acesso à filosofia, pois esta não se estende aos homens como um todo ${ }^{11}$.

Isso parece dizer respeito a certa compreensão orgânica de cidade, que Averróis parece ter herdado de Al-Farabi, ou que tenha sido orientada pela leitura da República de Platão, única obra comentada por ele (Cf. MENSIA, 2019, p. 42). Neste sentido, é importante considerar que a harmonia e a justiça da cidade

\footnotetext{
${ }^{11}$ Segundo BOU AKL (2019, p. 62), a posição de Averróis opera, na verdade, uma redução ao espaço da interpretação e não uma expansão de suas possibilidades. Outras leituras, como GIOVANNI (2019, p. 16) e BELO (2016, p. 30), indicam que o propósito de Averróis parece ser mais amplo, relacionando o exercício filosófico a uma atividade desenvolvida naturalmente pelo homem.
} 
estarão na justa realização de suas funções por parte de seus habitantes. Isso pressupõe certo nivelamento de funções, mas também impõe certa liberdade de caracterização, já que cada indivíduo tem diante de si um horizonte investigativo que lhe cabe ${ }^{12}$.

Neste sentido, a Lei revelada é um guia para todos os homens, mas é um farol que orienta cada homem em seu próprio caminho. Tanto a imposição de uma ortodoxia marcada por um literalismo estrito, quanto a de um regime que imponha uma orientação filosófica para a massa, parecem posições extremas, por desrespeitarem o sentido que o próprio texto sagrado indica, a saber, o de que cada homem assente da melhor maneira que lhe é possível. Segundo ele, deve-se ter cuidado em relação a este procedimento, pois a interdição aos textos de natureza demonstrativa deve ser feita apenas aos indivíduos que não apresentem a aptidão necessária: "o que devem fazer os líderes dos muçulmanos é proibir os livros deles que contêm a ciência a quem não esteja apto à ciência;” (AVERRÓIS, 2005, p. 57).

Mesmo um homem experimentado na ciência demonstrativa pode incidir em erro, já que a revelação contém passagens que permanecem misteriosas mesmo para esses homens. Por exemplo, a questão da vida futura, que é matéria de controvérsia por aparentemente não possuir uma interpretação possível acerca de sua natureza, mas apenas da obrigatoriedade de sua crença. Para Averróis, a crença na vida futura encarna o exemplo por excelência de uma temática cujo acesso investigativo deve ser restrito aos homens da ciência demonstrativa, enquanto os homens comuns devem conformar-se com a interpretação relativa às imagens. Visto que a compreensão de sua obrigatoriedade é um dos fundamentos do Islã, é patente que um crente não poderá negá-la em seu assentimento; desde que isso não ocorra, e também que a sua interpretação não incorra em algum tipo de inovação condenável, é totalmente aceitável que se constitua a partir de imagens.

Parece que aquele que erra a propósito dessa questão, se for um sábio, será desculpado - e aquele que estiver com a verdade será reconhecido e recompensado -, isto se ele reconhecer a existência real [a vida futura] e se interpretar de uma maneira qualquer essa vida futura, quer dizer, [se esta interpretação incidir] na característica desta vida futura e não em sua própria existência; e [ainda] se esta interpretação não levar à negação da existência atual. (AVERRÓIS, 2005, p. 57).

Além disso, Averróis considera que grande parte do expediente investigativo em relação à questão se constrói no sentido de fornecer uma interpretação adequada para a questão. É neste sentido que se coloca a tarefa do intérprete conhecedor da ciência demonstrativa. Sua investigação individual em busca de seu próprio assentimento permitir-lhe-á acessar premissas dialéticas e imagens, com as quais poderá construir recursos retóricos e dialéticos para os homens que não têm capacidades de acesso à ciência demonstrativa: "Quanto àqueles que não são homens de ciência, têm o dever de considerar [os enunciados referentes a essa questão] em seu sentido óbvio; o fato de interpretá-los seria, a respeito delas, infidelidade, porque isso leva à infidelidade" (AVERRÓIS, 2005, p. 53).

Visto que o alcance do termo médio por parte do investigador da demonstração o habilita a apontar imagens que estejam mais necessariamente em acordo com a questão a ser esclarecida, a função da filosofia parece ser complementar aquela da revelação, no sentido de ampliar a possibilidade de esclarecimento, tanto para quem já se conformou com a explicação retórica ou aproximada dialeticamente, quanto para os indivíduos que só aquietarão suas almas na investigação do termo médio. Como afirma Mensia (2019, p. 31), esta é uma lógica que possui múltiplas camadas, algumas evidentes, outras não. Este procedimento é

\footnotetext{
${ }^{12}$ Este aspecto propedêutico da vida em comunidade também pode ser observado em seu comentário à República de Platão: "Foi também esclarecido, na mesma passagem, que ou não é possível que alguém seja perfeito conforme todas essas perfeições ou, se isto for possível, é muito difícil. Mas isto pode ocorrer com frequência em muitos homens. Parece também que não é possível que alguém seja perfeito conforme alguma perfeição dentre essas perfeições, a não ser que seja ajudado por todos os outros, e que, assim, o homem precisa dos outros para obter sua perfeição. Por isso, o homem é naturalmente um animal político.” (AVERRÓIS, 2015, p. 39).
} 
fundamental, pois a gratuidade da revelação só se completa na realização daquilo que os homens possuem como possibilidade. O efeito da revelação só é completo quando o homem também converte sua capacidade em uma disposição positiva, e, posteriormente, em ato.

É importante considerar essa relação que o assentimento possui com a atualização da alma, pois a interpretação não é apenas uma imagem acessória, e não cabe a ela substituir a verdade que está, aparentemente, inacessível a certos homens, mas que, sem ela, não poderão tornar-se crentes. Este símbolo fornecido pelo filósofo não poderá ser algo distinto desta verdade, por isso a necessidade de que o intérprete se aproxime do sentido demonstrativo, que manifestaria o que Averróis chama de "sentido oculto" (AVERRÓIS, 2005, p. 47), mas que se trata da compreensão das duas condições a que o silogismo científico precisa atender, ou seja, a necessidade e a causalidade. Este sentido oculto estaria relacionado a uma compreensão mais ampla da criação, orientada por uma perspectiva universal.

\footnotetext{
[...] pois que, na maioria das vezes, só se detêm nos livros de demonstração as pessoas de disposições naturais superiores, e essa espécie de homens não erra, a não ser por falta de virtude prática ou por não ter procedido à leitura na ordem certa, ou por não ter a ajuda de um mestre. (AVERROIS, 2005, p. 57).
}

Esta responsabilidade se coloca de maneira frontal, pois o acesso de homens despreparados à demonstração não vai simplesmente conduzi-los ao erro. $O$ problema apontado por Averróis também diz respeito ao fato de que muitos homens, pretensos conhecedores do sentido oculto da revelação, se dedicam a conduzir homens, e o vício de interpretação em que incorrem é transmitido a outros homens, comprometendo não apenas a sua salvação. Para Averróis, os livros de demonstração devem ser ter seu acesso limitado a essas condições. Impedir estes homens capacitados deste acesso à demonstração constitui uma falta grave. “[...] porque é uma injustiça à classe mais perfeita dos homens e à classe mais perfeita dos entes; pois é justo que esta (a Lei) seja conhecida tal qual é por aqueles que estão dispostos a conhecê-la tal qual é: os homens da classe mais perfeita." (AVERRÓIS, 2005, p. 57).

Este parece ser um dos caminhos utilizados por ele para apontar que a filosofia desempenha um papel fundamental na própria constituição do que é o homem, participando de modo incontornável do escopo daquilo que constitui o racional. Seu estudo cumpre mais do que a simples recomendação; em alguns casos, é obrigatório ao assentimento de certos homens. Segundo Averróis, o convite é feito pela própria revelação, que convoca os homens ao conhecimento do criador.

Neste contexto, o filósofo é colocado em uma função central, desempenhando papel fundamental na condução dos homens cujo espírito de compreensão é limitado (BRENET, 2015, p. 05). Mas seu papel como guia possui certa característica dúbia, pois revela aos homens simples a possibilidade do assentimento por uma via comum, simbolicamente clara e em conformidade com a verdade. No entanto, sua atuação também é a de um guardião, que esconde o tesouro das mãos daqueles que não estejam em condições de contemplar seu brilho. Isto parece colocar o filósofo no centro exato da vida pública, da qual ele não poderá privar-se, mesmo que sua compreensão universal daquilo que os homens conhecem apenas a modo de parte os guie para fora deste mundo.

E também é importante considerar que o homem que adquire para si a obrigação religiosa de orientar outros homens, a partir de seu conhecimento dos aspectos obscuros da revelação, não pode se privar da vida pública. Pelo contrário, ele deve ocupar seu papel central na cidade como legítimo intérprete do texto sagrado. Esse é o tipo de vida que parece caber de maneira mais própria aos homens: aquele que lhes permita realizar suas naturezas no interior da cidade (Cf. GIOVANNI, 2019, p. 16).

A função de conduzir a massa dos homens simples continuará existindo, mas em conformidade com o papel investigativo dos praticantes da ciência demonstrativa, que guiará os homens conforme os resultados 
obtidos em sua investigação. Para Mensia (2019, p. 31), argumentos são apresentados como caminhos inferenciais que os crentes devem seguir em sua própria reflexão em direção à adesão religiosa. $\mathrm{O}$ que muda nessa relação é que a interpretação fornecida pelo filósofo estará em conformidade com o resultado de um silogismo demonstrativo, e não de uma premissa dialética que, por sua característica imprecisa, pode conter perigosas imprecisões. A demonstração contém a exatidão necessária para que seus objetos derivados, imagens e enunciados dialéticos, possam ser apreciados por todos os indivíduos de maneira equânime, distintos apenas no grau de exatidão, mas em conformidade com a verdade do objeto investigado. O papel do filósofo procurará completar o assentimento dos homens simples, cuja apreciação das imagens fornecidas por estes produzirá seu assentimento religioso em conformidade com a verdade. Ainda de acordo com Mensia (2019, p. 31): "Em sua construção, o Legislador prova não ser apenas um pedagogo perspicaz, mas também um bom lógico.”

\section{O assentimento religioso (Tasdiq) individual}

A compreensão de uma via difusa para o assentimento, que permita tanto a aproximação dos homens simples quanto a garantia da especificidade do assentimento próprio dos filósofos, traz consigo uma série de questões de ordem metodológica que precisam ser resolvidas no horizonte deste debate.

Isso também parece indicar que o avanço na compreensão do assentimento religioso está diretamente relacionado ao grau de aproximação que cada indivíduo provoca para si. O assentimento é gratuito a todos os homens, visto que a obra do criador mostra os efeitos de sua causa a todos os seres. O que parece não estar orientado para a mesma gratuidade é a natureza do assentimento, que, conforme dissemos acima, pode ser estabelecido de vários modos, mantendo a gratuidade do acesso, mas não a sua qualidade. Parece irrelevante considerar algo desta ordem, pois se pode objetar que o fundamental é alcançar o assentimento, mas a caracterização introduzida por Averróis não serve apenas para garantir o acesso dos homens simples a uma aproximação com o divino, tendo em conta que um indivíduo que alcance seu assentimento por meio da ciência demonstrativa não conseguirá assentir mais de outro modo. Impedi-lo de percorrer tal caminho é também barrar seu acesso à compreensão da revelação de um modo que lhe seja satisfatório (THOM, 2019, p. 81).

O que é o assentimento (tasdiq) religioso? Este, que podemos considerar como um dos atos fundantes da crença de todo o fiel ao Islã, é marcado por um movimento, como o próprio nome diz, de assentimento, onde o fiel se coloca submisso à revelação corânica, assumindo-a como regra e orientação fundamental para sua existência (Cf. SARRIÓ, 2015, p. 51). Tal movimento de conversão nada possui de simples, pois está envolvida aqui uma série de elementos dos quais depende sua plena realização, e que podem comprometê-la em muitos casos.

Podemos entender que a realização do assentimento se dá através de um duplo movimento, no qual a revelação, universal e objetiva, encontra-se de forma harmonizada com a estrutura individual da razão humana, operando uma transformação no interior dos indivíduos que colocam sua alma em conformidade com esta regra, por aceitá-la como a verdade (Cf. BELO, 2016, p. 38). O que Averróis parece considerar aqui é que as razões por meio das quais os indivíduos escolhem assentir são múltiplas, algumas mais complexas e elaboradas, que são alcançadas com muito esforço e dificuldade, mas que produzem um assentimento mais profundo por sua fundamentação, enquanto outras formas de assentimento são mais brandas por sua apresentação superficial, sendo mais facilmente produzidas, e também mais passíveis de desvios, por sua inexatidão.

A capacidade racional é o que fornece a possibilidade de assentir, pois é por meio dela que os homens encontram diante de si o horizonte de liberdade que lhes permite realizar essa escolha. É também por isso 
que diferem entre si nos níveis de assentimento, pois a racionalidade, enquanto efetivação individual da capacidade essencial dos homens, é que vai orientar a profundidade do assentimento. Por isso, Averróis não encontra uma justificativa possível na separação dos domínios, o filosófico e o religioso, senão em sua caracterização complementar e harmônica (Cf. BELO, 2016, p. 37), dado que a efetividade da racionalidade é também a expansão da possibilidade do conhecimento do divino, que, com isso, também amplia no homem a possibilidade de um assentimento religioso mais profundo, tanto em quem investiga quanto em quem é orientado pelo resultado da investigação de outrem. A filosofia não pode ser negada aos homens, pois é a expressão própria desta capacidade de assentir, a qual pode ser desenvolvida (Cf. TAYLOR, 2014, p. 458).

O resultado do assentimento religioso é a felicidade, e quanto mais efetivo o primeiro, mais plena será a realização do segundo. A instrução dos homens simples deve ter em mente a produção desta relação. E a diferença que se pode pensar em relação aos resultados que o assentimento produz nos homens simples e nos eruditos, diz respeito ao grau de aprofundamento que suas conclusões alcançam em relação a ele. Os homens comuns recebem a orientação de maneira suficiente a suas demandas individuais, de forma a produzir o assentimento que se conforme suficientemente a eles. Em outras palavras, seu aprofundamento é expresso de maneira suficiente, para sanar a inquietação de seu espírito, e não mais que isso.

Isso porque ele convocou o povo ao conhecimento de Deus - Louvado seja Ele - por um caminho mediano que se encontra além do baixo nível de conformismo imitativo e aquém da erística dos teólogos dialéticos; e alertou a elite para a necessidade do empenho radical no exame racional do Princípio da Lei. (AVERRÓIS, 2005, p. 83) ${ }^{13}$.

Ao filósofo não cabe apenas a suficiência, mas sua orientação se dá no sentido de alcançar um estado pleno, em que a resposta buscada se mostre de modo necessário e exaustivo, que é próprio da investigação demonstrativa. Aos homens comuns há a resposta suficiente para sanar suas demandas, enquanto aos homens da ciência há a autorização para que sua busca procure alcançar a plenitude (WOHLMAN, 2004, p. 589). O que muda é apenas o grau de aprofundamento. Averróis distingue por gradação as virtudes teóricas e práticas, colocando as primeiras na regência da segunda. A amplitude de alcance do conhecimento teórico coloca a orientação prática sob sua tutela, pois muitas vezes a prática está orientada para o individual e para o escopo das obrigações da existência, características das quais a virtude teórica se afasta por seu descompromisso com a individualidade ou com a ocasião.

Nos mesmos termos da relação supramencionada, é importante considerar a gradação que distancia estes elementos. Pois uma virtude de natureza prática é algo que Averróis considera como sendo algo próprio ao atendimento das necessidades humanas, que devem ser atendidas apenas em conformidade com sua necessidade, ao passo que a virtude teórica tem em vista o alcance de um objetivo maior, mais pleno em relação à simples satisfação de uma demanda. Para Averróis, as ciências teóricas preparam os homens para a prática, exatamente por contemplarem em seu ensino as situações individuais que estão envolvidas no âmbito prático.

O exemplo do médico pressupõe que este tenha em mente duas inclinações no exercício de sua ciência, sendo a primeira delas a cura de seus pacientes. Para curar um indivíduo, o médico aplica-lhe uma profilaxia que está em conformidade com o restabelecimento de um estado de equilíbrio das funções corpóreas, ou, em outras palavras, uma profilaxia que visa ao estabelecimento de uma condição de suficiência. Assim, não é possível curá-lo em demasia, mas apenas em conformidade com a medida de sua saúde.

\footnotetext{
${ }^{13}$ Isso também pode ser lido a partir do Tahafut al-Tahafut: "As massas devem aprender que o conhecimento humano não é suficiente para tratar esses problemas, e devem ir atrás do ensinamento que a Lei sagrada explica em seus textos, pois estes são ensinamentos dos quais todos podem participar e que são suficientes para o alcance de sua felicidade." (AVERROIS, 1954, p. 359 , tradução nossa).
} 
A correspondência é, com efeito, exata, pois a relação do médico com a saúde dos corpos é idêntica à relação do Legislador com a saúde das almas: o médico é aquele que busca a preservação dos corpos se há saúde, ou sua recuperação, se ela não existe mais; e o Legislador é aquele que aspira a isso mesmo para a saúde das almas. (AVERRÓIS, 2005, p. 73)..$^{14}$

Por outro lado, o médico possui também a inclinação de sua prática como ciência, que não o orienta a tornar-se apenas um médico "suficiente", mas sim a buscar o alcance da plenitude nesta ciência. No primeiro caso, a inclinação atende à suficiência necessária para o reestabelecimento do equilíbrio, enquanto na segunda inclinação o que se tem em mente é a superação desta insuficiência. São dois graus dentro de uma mesma orientação conceitual. Averróis parece considerar que não seja possível concebê-los de maneira distinta, senão com fins didáticos. Pois a realização de ambos se dá na efetivação da existência como prova da continuidade existente entre ambos os registros, que também apontam para a continuidade na relação existente entre o prático e o teórico.

É por essa razão que caberá ao filósofo guiar os homens que não são capazes por si de alcançarem este patamar teórico. O auxílio intelectual que lhes é fornecido atualiza esse estado potencial em suas almas, aumentando, ainda que de um modo superficial, sua disposição individual para o conhecimento. Lembrando que a ciência tem, para Averróis, a função de apresentar aos homens os efeitos da criação, revelando, indiretamente, a presença do criador nelas. Caberá aos homens que alcançarem essa compreensão da criação a tarefa de tentar produzi-la também nas almas dos homens que não atualizarem esta capacidade.

Essa distinção das classes de homens também significa a distinção dos níveis possíveis em que os homens podem compreender o texto sagrado, bem como da profundidade dos níveis de assentimento religioso que podem ser alcançados por eles. A escritura manifesta perfeitamente a verdade, atendendo a todos os homens; a distinção destas formas diz respeito a limitações que são próprias dos seres compostos e, por mais que a ciência de um indivíduo possa ser desenvolvida perfeitamente em ato, ela apenas dá conta de uma perspectiva limitada da revelação, que se resume à sua própria condição de assentimento. É por essa via difusa que o Livro Sagrado atende a todos os homens como revelação, como pode ser lido na passagem: "Assim, como nossa lei divina convoca os homens por meio destes três caminhos, deve ser generalizado o assentimento de toda a gente, exceção feita àqueles que (por sua própria negligência) não têm estabelecidos os caminhos que levam ao conhecimento de Deus - O Altíssimo.” (AVERRÓIS, 2005, p. 21).

Para cada tipo de homem há um assentimento. Averróis distingue especificamente três modos de assentimento, que equivalem a três naturezas de homem. O primeiro é o daqueles que encontram seu assentimento por meio de argumentos retóricos, homens que possuem pouco desenvolvimento no que tange ao conhecimento, e que se limitam quase exclusivamente ao nível das imagens sensíveis no que diz respeito a seu conhecimento individual (BUTTERWORTH, 1972, p. 900). Estes são os homens que dependem, muitas vezes, para que seu assentimento se complete, de outros homens mais instruídos que lhes forneçam a orientação para que sejam instruídos na religião. $\mathrm{O}$ segundo tipo de assentimento é produzido nos homens que estão um nível acima da retórica, mas que ainda sim têm o assentimento assentado provisoriamente em argumentos dialéticos, possuindo a capacidade de formular hipóteses sobre as questões religiosas, mas que têm suas conclusões prejudicadas pelo caráter contingente de suas hipóteses. Geralmente, operam com generalizações do senso comum, chegando a alcançar algumas premissas adequadas para uma investigação, no entanto, carecem da precisão que o silogismo demonstrativo fornece a suas conclusões. Já o terceiro tipo de assentimento é produzido nos homens que praticam a

\footnotetext{
${ }^{14}$ Averróis recorre a esse tipo de exemplo em outras obras, como é possível observar no Tahafut al-Tahafut: "E assim como o médico investiga a medida da saúde que está em acordo com o saudável para a preservação de sua saúde, e com o doente para a cura de sua doença, assim o homem da Lei sagrada instrui as massas apenas na medida do necessário para a aquisição de sua felicidade." (AVERRÓIS, 1954, p. 258, tradução nossa).
} 
ciência demonstrativa. Para Averróis, são estes homens que possuem a capacidade de emitir julgamentos corretos relativos a questões de natureza religiosa.

De fato, existe diversificação das naturezas humanas no que toca ao assentimento: há os que assentem pela demonstração; outros que assentem por meio dos argumentos dialéticos, semelhante ao assentimento da demonstração, pois suas naturezas não os dispõem para mais do que isso; e há os que assentem pelos argumentos retóricos, assentimento semelhante ao dos que assentem à demonstração por argumentos demonstrativos. (AVERRÓIS, 2005, p. 19).

Todos os homens são criados igualmente por Deus e possuem a mesma capacidade racional. No entanto, ainda que dotados de maneira equânime desta capacidade, o assentimento será caracterizado por uma questão volitiva, e o que Averróis aponta como sendo um erro cometido por parte dos teólogos (Mutakallimun $)^{15}$ também se relaciona a isso. Os homens comuns assentem por meio de argumentos retóricos, e os teólogos se esforçam no sentido de produzir tais estruturas para conduzir este assentimento.

Seu erro estaria concentrado no uso de proposições dialéticas, incompletas, como tais, em suas conclusões, criando problemas de ordem conceitual, como a própria concepção de que demonstração e texto sagrado são incompatíveis. Para Averróis, esta incompatibilidade apontada por estes homens é fruto de sua compreensão superficial do texto sagrado, fazendo deles pretensos estudiosos, responsáveis pelo mau uso das ciências na condução do assentimento dos homens simples, de modo que tentam igualar a mensagem da revelação, nivelando-a conforme sua própria compreensão. Estes homens ocupariam uma posição problemática no que concerne a seu assentimento, não alcançando a compreensão do conhecimento demonstrativo, que não são capazes de conhecer com clareza, pois seus argumentos são dialeticamente orientados. Seriam estes os responsáveis por confundir os homens simples por meio de sua própria incompreensão (Cf. BELO, 2016, p. 45).

A introdução de tal limitação é que constitui, para Averróis, o erro que afasta os homens do assentimento religioso, pois a revelação contém a amplitude necessária para que os níveis sejam igualmente válidos, e que todos os homens possam assentir do modo que lhes seja mais adequado. Averróis, sobre este ponto, cita uma passagem do Corão, para justificar que sua exortação é apenas o que já está manifesto no próprio Livro Sagrado: "Chama ( $\left.y d a^{\prime} a u\right)$ os homens para o caminho de teu senhor, pela sabedoria e pela bela exortação, discute com eles do melhor modo." (AVERRÓIS, 2005, p. 21$)^{16}$

Um efeito decorrente desta perspectiva é que o assentimento, enquanto efeito ocorrido no interior da alma dos indivíduos, permanece o mesmo em todas as classes de homens, mas o grau de aprofundamento e conhecimento é que se torna próprio a cada um deles.

Dizemos, então: tendo em conta que o propósito da Lei religiosa é o ensino da ciência verdadeira e da prática verdadeira e que tal ensino é de duas espécies: da representação e do assentimento como foi ressaltada pelos lógicos (ahl al-ilmbil-kalam); e que os métodos do assentimento para os homens são três: o demonstrativo, o dialético e o retórico; e que os métodos de produção da representação são dois: representação da coisa em si, ou de seu similar: tendo em conta que nem todos os homens, por sua natureza, dispõem-se a aceitar demonstrações e mesmo argumentos dialéticos, e menos ainda argumentos demonstrativos!, além da dificuldade de aprendizagem dos argumentos demonstrativos e o longo tempo que se requer da parte daqueles que são aptos para tanto; e que

\footnotetext{
${ }^{15}$ Um mutakallim é um estudioso do Kalam.

${ }^{16}$ Surata 16 , ayat 125 .
} 
o propósito da Lei é o de ensinar todos os homens, era preciso necessariamente que a Lei abrangesse todos os tipos de método de produção da representação. (AVERRÓIS, 2005, p. 61) ${ }^{17}$.

Isso parece estar de acordo com o que é proposto por ele como a orientação interpretativa supracitada, isto é, que o nível de proximidade de cada fiel com a salvação dependerá exclusivamente de seus esforços e de suas escolhas, enquanto a revelação, o vínculo de todos os homens com o criador, fonte da verdade, é gratuitamente assegurada a todos. A racionalidade é uma capacidade inerente a todos os indivíduos da espécie humana; sua efetivação como disposição positiva é que depende das inclinações individuais (Cf. BELO, 2016, p. 31).

É importante considerar que esta relação pode ser um dos modos possíveis de relacionar sua leitura da filosofia de Aristóteles com a escatologia islâmica, visto que este é um dos problemas que a discussão a respeito da legitimidade da filosofia em face da revelação imputará aos falasifah, ou seja, o de conduzir os homens a uma compreensão paralela da verdade, distanciada daquela orientada pelo texto revelado. Averróis parece buscar nestes elementos a possibilidade de integração entre os dois registros, o religioso e o filosófico.

E isto consiste em também estabelecer como o exercício da filosofia, a especulação orientada pela demonstração, poderá ser associada e - por que não? - incorporada à vida prática. Interessante notar que o termo "harmonia", manifesto no Fasl al-maqal, parece não estar orientado por uma possibilidade simples de relacionar os dois registros, mas sim de pensar sua continuidade natural, ou, em outras palavras, aquilo que é manifesto no termo Harmonia. Fazer de tal orientação um guia prático para a vida também vai conduzir a um regime que determina e orienta a aquisição e a caracterização do assentimento religioso corretamente guiado para o que determina a revelação. Neste sentido, a caracterização da conjunção proposta por Averróis tem como uma de suas consequências essa orientação prática, que integra o papel do filósofo ao centro da sociedade, e que também eleva os homens simples a uma participação mais efetiva no que tange ao florescimento de sua própria capacidade intelectual.

Além disso, o discurso sobre o assentimento estará fortemente associado ao movimento individual da vontade como motor das ações individuais, orientado pelas imagens, no caso dos homens simples, e também pela ciência demonstrativa, no caso dos praticantes desta ciência. Também é importante considerar aqui que esta característica difusa, que orienta os caminhos do assentimento, tem relação direta com a manutenção do caminho próprio que cada indivíduo deve seguir nesta matéria. Pois os homens devem assentir conforme sua própria natureza, assentimento que é marcado, de maneira individual, pelo caminho a ser seguido por cada um. O impulso de sua própria natureza é que vai determinar o tipo de assentimento que cabe a cada homem. (TAYLOR, 2014, p. 457)

Averróis afirma que há homens que possuem uma capacidade inata para a filosofia. Importante considerar isso no horizonte desta tese, pois afirmar que cada homem vai assentir do modo que se lhe seja próprio parece conduzir-nos a pensar que Averróis está concebendo que todos os homens sejam iguais, e isto que pode ser considerado como uma possibilidade de escolha talvez esteja completamente orientado pela natureza. De fato, por sua natureza composta, considerada a partir de sua definição, todos os homens serão iguais. No entanto, há um sentido para a revelação, que parece constituir para certos homens uma inclinação diferente, e, seja para os profetas, seja para os homens comuns, tal inclinação já está determinada. É isso que parece guiar o discurso de Averróis a respeito das naturezas dos homens, e

\footnotetext{
${ }^{17}$ Algo semelhante a isso também pode ser lido no Tahafut al-Tahafut: "E desde que a existência da classe esclarecida só é aperfeiçoada e tem sua felicidade última alcançada pela participação na classe das massas, a doutrina geral é também obrigatória para a existência e a vida desta classe especial, tanto no momento de sua juventude e crescimento (e ninguém duvida disso) quanto quando eles passam a alcançar a excelência, que é sua característica distintiva.” (AVERRÓIS, 1954, p. 360, tradução nossa).
} 
também o que parece balizar a afirmação de que há homens que estejam naturalmente inclinados para a filosofia (Cf. TAYLOR, 2014, p. 458).

\section{Considerações finais}

Seria precipitado afirmar que Averróis está, exclusivamente, defendendo a filosofia de Aristóteles como modo, por excelência, de praticar a ciência. Mas é neste sentido que seus argumentos parecem indicar que a análise demonstrativa é aquela ciência que possui a capacidade de se aproximar de um conhecimento verdadeiro a respeito de seu objeto. E tais homens é que seriam os legítimos intérpretes do texto revelado.

Mas proibir totalmente [os livros de demonstração] significa barrar o acesso a alguma coisa que Revelação chama a praticar; porque é cometer uma injustiça à classe mais perfeita dos humanos, e à classe mais perfeita dos seres. Pois é um bem que esta (a Lei) seja conhecida tal como ela é por aqueles que estão dispostos a conhecê-la tal como ela é: os homens da classe mais perfeita (AVERRÓIS, 2005, p. 57).

Cabe considerar que o erro nessa matéria será orientado por um acidente, seja no tratamento das premissas, seja na imagem utilizada para tanto. $\mathrm{O}$ erro é um aspecto do horizonte investigativo que não pode ser abandonado pelo investigador, visto que não reside especificamente na demonstração, mas no indivíduo que a conduz. É importante que a ciência demonstrativa esteja sob a tutela de homens capazes, pois somente deste modo é possível evitar ao máximo ou, ao menos, minimizar a possibilidade deste erro.

Dentre os inimigos da posição filosófica, talvez o mais notável entre eles seja al-Ghazali, que acusa os filósofos de introduzirem elementos que não são admitidos tradicionalmente pela interpretação. Ao fazerem isso, estes homens estariam introduzindo "inovações condenáveis" (bid'a), i.e., realizando a introdução de elementos ou práticas que não possuem respaldo na Lei revelada ou mesmo na tradição, algo que promove a modificação na estrutura da religião. Uma inovação condenável é um crime sujeito a punição.

Esta definição de filosofia utiliza-se do convite expresso no Livro Sagrado para colocar-se como um elemento central que guia para uma espécie de prova da existência de Deus. Isso parece assegurar a permanência da investigação filosófica como válida e necessária, sem desvincular a religião de sua posição prioritária. O exercício filosófico é um dos elementos inscritos na capacidade racional que tem a função de aproximar o homem do conhecimento de Deus.

E se a Lei divina é a verdade, e se ela convida a praticar o exame racional que leva ao conhecimento da verdade, então, certamente, nós, da comunidade dos muçulmanos estamos convencidos de que a especulação demonstrativa não pode conduzir a conclusões diferentes daquelas contidas na Lei, já que a verdade não contraria a verdade, mas concorda com ela e dá testemunho em favor dela. (AVERROIS, 2005, p. 21).

Neste sentido, é necessário considerar que a demonstração não é apenas uma ciência que tem como função o conhecimento dos entes e suas relações necessárias, mas sim uma ferramenta por excelência que fundamenta a crença religiosa e que dá suporte ao assentimento religioso dos homens. Isso naturaliza o papel do conhecimento filosófico como a fonte para o conhecimento do criador.

A religião é própria aos seres racionais, por isso a sua manifestação deve ser distribuída igualmente por toda a humanidade, o que não é algo outro que a manifestação da verdade que se coloca disponível aos seres racionais como sua potência para ser. Todo indivíduo que se afasta deste propósito o faz introduzindo limitações nas manifestações relativas à verdade, apontando que há contradições inerentes à sua busca, reduzindo-a a um único método de obtenção.

Isso não passa de um mecanismo de controle, que priva a manifestação da amplitude própria à revelação. Para Averróis, o próprio Corão demanda dos homens a procura pelo conhecimento e pelo exercício da razão. E isto não representa apenas um guia definitivo para a verdade, mas também inclui um aspecto 
didático pedagógico evidente, um convite à prática racional. Se podemos dizer que o objetivo da revelação é o alcance de todos os homens, sua mensagem parece ter mais relação com uma condução da maior parte dos homens, por isso os sinais dos homens da ciência demonstrativa estão ocultos e precisam ser pesquisados. Para ele, os praticantes desta ciência constituem a elite intelectual, pois são capazes de percorrer esses sinais ocultos na revelação.

É preciso que saibamos que o propósito da Lei é exatamente: ensinar a ciência verdadeira e a prática verdadeira.
A ciência verdadeira é o conhecimento de Deus - Bendito e exaltado seja - e do conjunto dos seres existentes tal
qual são - em especial dos mais honrados entre eles - e o conhecimento da bem-aventurança e dos tormentos da
outra vida. E a prática verdadeira consiste no cumprimento de atos que garantam a bem-aventurança e no evitar
atos que levem aos tormentos. O conhecimento destes atos chama-se ciência prática. (AVERRÓIS, 2005, p. 59).

Os homens simples estariam limitados por uma questão de inclinação, e seu processo de conhecimento permaneceria estacionado em um estágio intermediário, o da produção de imagens individuais, que pode ser caracterizado como sem acesso a inteligíveis, pois seu conhecimento está limitado, no que tange ao processo de sua construção, ao horizonte da sensação, imaginação e cogitação, não alcançando a intelecção propriamente dita. Sem finalizar adequadamente este processo, os homens simples não produziriam para si os inteligíveis especulativos, que constituem a transformação da capacidade de conhecer em uma disposição positiva para tal atividade, já que o conhecimento humano é constituído pela aquisição sucessiva de formas, progressivamente aumentando em complexidade de universalidade, em um processo que tem como orientação um espelhamento gradual com a atividade do intelecto agente. Essa compreensão se deve, pois, a um sentido que, por sua nobreza, não pode ser capturado imediatamente, dado que não se trata de algo evidente. $\mathrm{O}$ conhecimento literal, imediato, revela de maneira suficiente aquilo que o texto sagrado manifesta, fornecendo as condições básicas de assentimento. Já o sentido oculto, que não é imediato, só é obtido pelo exercício da ciência demonstrativa, sendo capaz de apreender o todo da questão, abarcando os dois sentidos (Cf. WOHLMAN, 2004, p. 593).

O caso utilizado como exemplo, a imortalidade da alma, trata-se de uma questão cuja problemática reforça este aspecto educativo da posição do filósofo na interpretação do texto sagrado. O sentido da vida futura não é compreendido com clareza pelos homens simples, sendo lícito, neste caso, que o intérprete da escritura possa utilizar-se de imagens para explicar este fundamento: "Para a elite, entretanto, é um dever interpretar esse tipo de argumento, e o dever do povo é prender-se no sentido óbvio." (AVERRÓIS, 2005, p. 65).

Algumas passagens do texto sagrado estão destinadas à elite intelectual, pois apenas estes homens conseguem compreender quando utilizar corretamente os dois sentidos. Diante de uma possível contradição, o sentido literal é sempre preferível, pois há passagens no texto que são de difícil compreensão mesmo para os investigadores da demonstração, como é o caso da vida futura, tema sobre o qual nenhum fiel coloca em dúvida sua existência, mas também se sabe que sua descrição varia muito em suas particularidades. Voltarse para o sentido literal da escritura é proteger seu sentido primário imediato. Ademais, a incompreensão aparente de alguma passagem do texto e o retorno à sua literalidade indicam um horizonte prático, de maneira que, embora a reflexão esteja adiada pela incompreensão, o sentido literal apresentará uma saída prática - ainda intermediária, mas suficiente para que o fiel não fique sem a orientação da revelação (Cf. TAYLOR, 2000, p. 11).

Em suma, não importa qual destas vias se tome para o assentimento, o texto sagrado cumprirá seus dois propósitos, o de revelar aos homens o conhecimento de Deus, e o de orientar a virtude prática relacionada a ele. Em resumo, a verdadeira ciência e a verdadeira prática. O primeiro destes propósitos é o que Averróis relaciona diretamente com a prática filosófica, pois diz respeito ao conhecimento do Criador por meio de suas obras. A prática está implicada nos caminhos possíveis para o assentimento religioso, guiando os homens para sua identificação com o Criador. Estas duas instâncias completam o cômputo das atividades 
que são próprias aos animais racionais: inteligir e agir. Se o médico tem como seu objetivo a manutenção da saúde, aquele que legisla sobra a lei religiosa tem em vista a saúde das almas. Conduzir os homens a um estado bem-aventurado é o que Averróis considera como sendo a fonte para a felicidade nesta existência e no horizonte da vida futura.

\section{Referências bibliográficas:}

Livros:

Al-KINDI. A Filosofia Primeira. Trad. Miguel Attie Filho. São Paulo: Attie Produções Ltda, 2014.

AVERROES. Discours Decisif. Trad. Marc Geoffroy. Paris: GF Flammarion, 1996.

AVERRÓIS. Discurso decisivo. Tradução de Márcia Valéria Aguiar. São Paulo: Martins Fontes, 2005.

\&Co., 1976.

. On the Harmony of Religion and Philosophy. Trad. George F. Hourani. Londres: Luzac

. Fasl al-maqal o Doctrina decisiva y fundamento de la concordia entre la revelación y la ciencia, Trad. Manuel Alonso. In: Teología de Averroes: estúdios y documentos. Madrid/Granada: Consejo Superior de Investigaciones Científicas, 1947.

. Averroè: Il trattato decisivo, sull'accordo dela religione com la filosofia, Trad. Massimo Campanini. Milão: Biblioteca Universale Rizzoli, 1994.

. Fasl al-maqal, Trad. Rafael Ramón Guerrero. In: Sobre Filosofia y Religión. Pamplona: Universidad de Navarra, 1998.

Doctrina decisiva (Fasl al-maqal) y fundamento de la concordia entre la ley religiosa (la revelación) y la sabiduría (la filosofia general) de Ibn Roshd (Averroes), trad. Vera Yamuni Tabuch. In: Selección de Lecturas: História de la Filosofia II, Edad Media y Renacimiento. México: Universidad Nacional Autónoma de México, 1996.

der Weltreligionen, 2010.

.Fasl al-maqal, trad. Frank Griffel. In: Ibn Rushd, Maßgbliche Abhandlung. Berlim: Verlag

. Discurso decisivo sobre a harmonia entre a religião e a filosofia, trad. Catarina Belo. Lisboa: Imprensa Nacional Casa da Moeda, 2006.

. Comentário sobre a "República", trad. Anna Lia A. de Almeida Prado e Rosalie Helena de Souza Pereira. São Paulo: Perspectiva, 2015.

. The Book of the Decisive Treatise: and, the Epistle Dedicatory. Translated by Charles E. Butterworth. Utah: Brigham Young University Press, 2008.

. Averroes' Tahafut al-tahafut: (The incoherence of the incoherence). Tradução de Simon Van den Bergh. London: Oxford University Press, 1954.

ADAMSON, P. et GIOVANNI, M. Interpreting Averroes/Critical Essays. Cambridge: Cambridge University Press, 2019. 
BELO, C. Averroes and Hegel on Philosophy and Religion. London and New York: Routledge, 2016.

JOLIVET, J. Multiple Averroès. Actes du Colloque International organisé à l'occasion du 850 anniversaire de la naissance d'Averroès. Paris: Les Belles Lettres, 1978.

NANJI, A. The Penguin Dictionary of Islam. Penguin Books UK, 2008.

PSEUDO-ARISTÓTELES. Teologia de Aristóteles. Obras Completas. Lisboa: Casa da Moeda, 2005.

WOHLMAN, A. Al-Ghazali, Averroes and the Interpretation of the Qur'an: Common Sense and Philosophy in Islam. USA and Canada: Routledge, 2010.

URVOY, Dominique. Averroes, Las ambiciones de um intelectual musulmán. Madrid: Alianza Editorial, 1998.

Artigos:

BUTTERWORTH, C. Averroes on Law and Political Well-Being. In: Averroes et les Averroismes Juif et latin. Turnhout: Brepols Publishers, 2007, p. 183-192.

. Politics and Opinion. In: The American Science Review, Vol. 66. Cambridge:

American Political Science Association, 1972, p. 894-901.

CAMPANINI, M. Averroes' hermeneutics of the Qur'na. In: Averroes et les Averroismes Juif et latin. Turnhout: Brepols Publishers, 2007, p. 215-230.

FAERJAT, L. Razones y Argumentos: Uma Relectura del Fasl al-maqal de Averroes. In: Estudios de Asia e África, Vol. 49, n. 01, 2014.

FAKHRY, M. Philosophy and Scripture in the Theology of Averroes. In: Mediaeval Studies, Vol. 68. Brepols Publishers: 2006, p. 78-89.

GEOFFROY, M. L'almohadisme théologique d'Averroès (Ibn Rusd). In: Archives d'histoire doctrinale et littéraire du Moyen Age, Vol. 66, p. 09-47. Paris: Livrairie Philosophique J. Vrin. 1999.

GIOVANNI, M. Averroes, Philosopher of Islam. In: Interpreting Averroes/ Critical Essays. Cambridge: Cambridge University Press, 2019, p. 09-26.

HOURANI, G. Averroès Musulman. In: Multiple Averroès. Paris: Les Belles Letres, 1978, p. 21-32.

LEAMAN, O. Ibn Rushd on Happiness and Philosophy. Studia Islamica, No. 52 (1980), p. 167-181.

MAHDI, M. Remarks on Averros Decisive Treatise. In: Islamic Theology and Philosophy, Studies in honour of G. F. Hourani. Albany: State University of New York Press, 1984, p.188-203.

MAKKI, M. Contribución de Averroes a la ciencia jurídica musulmana. In: Al Encuentro de Averroes. Madrid: Editorial Trotta, 1993, p. 15-38.

MENSIA, M. A. Dogmatics, Theology, and Philosophy in Averroes. In: Interpreting Averroes/ Critical Essays. Cambridge: Cambridge University Press, 2019, p. 27-44. 
SARRIÓ, D. R. The Philosopher as the Heir of the Prophets: Averroes's Islamic Rationalism. In: AlQantara, XXXVI 1, 2015.

TAYLOR, R. Providence in Averroes. In: Fate, Providence and Moral Responsibility in Ancient, Medieval and Early Modern Thought. Leuven: Leuven University Press, 2014, p. 455-472.

. Truth does not Contradict Truth: Averroes and the Unity of Truth. In: Topoi, 19.1. 2000, p. 03-16.

. Averroes on the Sharî'ah of the Philosophers. In: The Muslim, Christian, and Jewish Heritage: Philosophical and Theological Perspectives in the Abrahamic Traditions. Richard C. Taylor \& Irfan Omar, eds. (Marquette University Press, Milwaukee, 2012), p. 283-304.

THOM, P. Averroes' Logic. In: Interpreting Averroes/ Critical Essays. Cambridge: Cambridge University Press, 2019, p. 09-26.

WOHLMAN, A. Les deux facettes de l'unique vérité. Revue Thomiste, Vol.104. 2004, p. 579-600.

Recebido em 01 de julho de 2020. Aceito em 17 de agosto de 2020. 